\title{
East African Institute of Social Research: Applied Research Unit
}

Thrs Unit was established with a grant from the Ford Foundation, and started work in July 1960. The aim of the Unit is to stimulate interest in, and responsibility for, social and economic research in public, business and voluntary bodies in East Africa. Projects now in progress include a study of the social and economic consequences of land enclosure in Kipsigis Reserve, a socio-economic survey of Luo churches in Nyanza Province, and a study of Kikuyu urbanization in Nairobi. A number of projects will start shortly-ethnographic surveys of small tribes in Tanganyika; studies of urban delinquency in Kampala; socio-economic studies of the production of cotton in Uganda; a socio-economic study of the land consolidation in Kikuyu-land. Further plans include the economics of game utilization and transport and retail trade in Tanganyika. Further information on the Applied Research Unit may be obtained from the Research Secretary, Dr. Derrick J. Stenning, E.A.I.S.R., Makerere College, P.O. Box 262, Kampala, Uganda.

\section{Archaeological Discoveries in Niger Province}

AN archaeological site of great potential interest has been discovered in a remote valley named Taruga neat Takushara, about forty miles south-east of Abuja in Niger Province. Two headless terra cotta figurines in the Nok style were found there and were generously presented to the Jos Museum last September, a few days before the celebration of Independence, by Mr. N. de B. Priestley, owner of the tantalite mine of Takushara.

A cursory examination of the site at the end of November convinced the Director of Antiquities, Mr. Bernard Fagg, that excavations might yield important results, as the deposits in which the figurines were found appeared to be in situ, whereas all other finds of Nok figurines within the Nigerian Minesfield had been found in alluvial deposits, where the associated evidence is of limited value. Mr. Fagg has made a ten-day preliminary excavation of a corner of the site which has confirmed that the figurines do in fact occur in an undisturbed occupation site of about four feet thick, whose precise character is still unknown but which may prove to extend to about ten acres and to be a village site, possibly containing iron-smelting furnaces. Among material found in situ, in addition to fragmentary figurines in the Nok style (including the missing head of one of the figurines which led to the discovery), are pottery dishes of a very sophisticated design and unique decoration. The thorough exploration of this area and the excavation of a substantial part of the occupation site are expected to take several years and will, it is hoped, increase our knowledge of this early period in the history of Nigeria.

During the excavations the site was visited by Alhaji Hassan, Hakaman Abuja and a member of the Antiquities Commission, who was able to give valuable assistance in helping to establish that no folk memory of any settlement in this valley exists among the Gwari, Gwandara and Gade of the neighbouring villages. This is consistent with the physical appearance of the deposits which suggests a temote anitiquity.

\section{'A Contribution to the Study of Zande Culture': A Correction}

A LetTer from Professor E. E. Evans-Pritchard in Man (1x, December 1960, 235) points out an error in the table on p. 3 Io of his paper 'A Contribution to the Study of Zande Culture' (Africa, 4, 1960, pp. 309-24). The Abangbinda are listed in the table as being Sudanic, but they are a Bantu people and should have been listed as such. 